\title{
Neutron Imaging of Soil Rhizosphere \& Root Water Dynamics
}

\author{
JEFFREY M WARREN ${ }^{1 *}$, HASSINA Z BILHEUX ${ }^{1}$, EDMUND \\ PerfeCT $^{2}$, KeITA DECARLO $^{3}, \mathrm{KATIE} \mathrm{MARCACCI}^{2}$, \\ JEAN-CHRISTOPHE BILHEUX ${ }^{1}$
}

${ }^{1}$ Oak Ridge National Laboratory, Oak Ridge, TN 37831 , USA; (*correspondence: warrenjm@ornl.gov; bilheuxhn@ornl.gov, bilheuxjm@ornl.gov)

${ }^{2}$ University of Tennessee, Knoxville, TN 37996, USA; (eperfect@utk.edu, kmarcacc@,vols.utk.edu)

${ }^{3}$ Princeton University, Princeton, NJ 08544, USA; (brownplants@gmail.com)

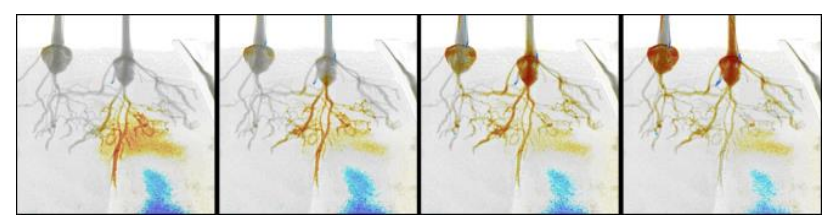

Attenuation-based neutron radiography and computed tomography are currently utilized for the study of plant-soil interactions. Results with various woody plants, maize and switchgrass indicate significant variability in water dynamics across the soil-rhizosphere-root pathway, including root water uptake and hydraulic redistribution, hysteresis in water release curves and soil wettability. Measured root water extraction rates by cottonwood ranged from 0.003 to $0.02 \mathrm{~g}$ $\mathrm{cm}^{-2} \mathrm{~h}^{-1}$, with lower rates for larger roots. Across species, root rhizosphere development increases with root size, stabilizing as roots reach $\sim 2 \mathrm{~mm}$ in diameter. Analysis required development of a novel 'RootProcessing' image analysis software to identify and segment roots, and analyze root, rhizosphere and soil water dynamics. Neutron radiography has also indicated significant root and mycorrhizal impacts to the soil hydraulic parameters, including hydraulic conductivity and residual water content. While bulk water dynamics are readily visible using neutron radiography, alternate or novel techniques are needed to assess higher resolution water dynamics (e.g., $<50 \mathrm{um}$ ), symbiotic rootmicrobial relationships, development of gaps across the rhizosphere that can isolate the root from the soil, and critically, nutrient or ion uptake dynamics. 